VIII Congresso Brasileiro de Informática na Educação (CBIE 2019)

Anais do XXV Workshop de Informática na Escola (WIE 2019)

\title{
Criação de Jogos Educacionais para apoiar o Ensino da Matemática: um Estudo de Caso no Contexto da Educação 4.0
}

\author{
Deivid Eive Silva1, Marialina Corrêa Sobrinho², Natasha Malveira C. Valentim ${ }^{1}$ \\ ${ }^{1}$ Universidade Federal do Paraná (UFPR), Curitiba - PR - Brasil \\ ${ }^{2}$ Universidade Federal do Oeste do Pará (UFOPA), Santarém - PA - Brasil \\ \{dessilva@inf.ufpr.br, linasobrinho@gmail.com, natasha@inf.ufpr.br\}
}

\begin{abstract}
Resumo. Os profissionais de hoje precisam ser capacitados para superar as atividades repetitivas. Assim, cabe à escola promover situações que possibilitem aos estudantes desenvolver as competências e habilidades que são requeridas no século XXI. Esta prática redefine a Educação, conhecida como Educação 4.0. Neste contexto, esse artigo apresenta um estudo de caso que teve o objetivo de desenvolver o pensamento computacional por meio da criação de jogos educativos, tendo a Matemática como disciplina de apoio. Com a pesquisa desenvolvida, foi percebido que o ensino da computação por meio da criação de jogos é interessante para a aprendizagem, pois instiga a curiosidade do aluno e melhora a formação escolar.
\end{abstract}

\begin{abstract}
Today's professionals need to be trained to overcome repetitive activities. Thus, it is the role of the school to promote situations that allow students to develop the skills and competencies that are required in the 21 st Century. This practice redefines Education, known as Education 4.0. In this way, this paper presents a case study that aims to develop computational thinking through the creation of educational games, it's had mathematics as a support discipline. With the research developed, it was noticed that the teaching of computing through the creation of educational games is interesting in learning because it instigates the student's curiosity and improve the school education.
\end{abstract}

\section{Introdução}

A tecnologia da informação está presente nos variados setores da sociedade, desde pequenos estabelecimentos comerciais até lugares de grande porte como a indústria. Da mesma forma, para desenvolver competências, como solucionar desafios diários e resolver problemas diversos, o uso da tecnologia tem se demonstrado eficaz. Hoje, na Educação Básica são promovidas iniciativas para introduzir o ensino da computação, e isso tem provocado bons resultados no desempenho dos estudantes [Oliveira et al. 2017].

Nesse sentido, foi percebida a necessidade de uma formação escolar mais alinhada ao mundo contemporâneo que prepare o aluno para lidar com os desafios do Século XXI. Essa necessidade ocorre, principalmente diante do atual processo de digitalização das empresas, conhecida como Indústria 4.0. Na Indústria 4.0 muito se discute sobre qualificação profissional dos jovens para atender as recentes mudanças sociais. Este é um novo parâmetro que redefine o formato de educação, conhecida como Educação 4.0 [Puncreobutr 2016]. 
VIII Congresso Brasileiro de Informática na Educação (CBIE 2019)

Anais do XXV Workshop de Informática na Escola (WIE 2019)

O ensino da computação por meio da Linguagem de Programação tem se demonstrado importante nos processos de ensino e aprendizagem da Educação 4.0, principalmente para instigar o pensamento computacional, ou seja, a capacidade de resolver problemas de forma sistemática [Aono et al. 2017]. Desse modo, a Base Nacional Comum Curricular [BNCC 2017] incentiva o uso dos recursos tecnológicos para enriquecer as formas de ensinar e aprender. Este incentivo acontece, pois o ensino da computação nas escolas pode possibilitar o aluno lidar com diferentes fontes de informação para adquirir e construir o conhecimento de maneira criativa e inovadora.

Nesse sentido, a proposta deste trabalho é desenvolver o Pensamento Computacional, tendo a Matemática como disciplina de apoio. Acredita-se que por meio do Pensamento Computacional será possível apoiar a resolução de problemas que é uma das competências requeridas no Século XXI. Assim, o estudante poderá entender problemas e utilizará o computador para resolvê-los, pensará de maneira lógica e sistemática, fará representações por meio das simulações, automatizará soluções por meio do pensamento algorítmico, entre outros. Dessa maneira, o Pensamento Computacional pode contribuir diretamente com os desafios da Educação 4.0 que é preparar os estudantes para lidar com a tecnologia e os processos tecnológicos.

A metodologia do trabalho está apoiada na teoria Construcionista de [Papert 1994] que define que "o indivíduo é o próprio construtor do seu conhecimento". As atividades foram orientadas pela Espiral do Saber desenvolvida por [Resnick 2007]. A ferramenta adotada para a realização do projeto foi o Scratch, onde o aluno pode criar sua própria estória, jogos e animações. Nesse estudo de caso foi abordada a lógica de programação e as operações aritméticas (soma, subtração, multiplicação e divisão) com alunos do $5^{\circ}$ ano do Ensino Fundamental I. Dessa forma, acredita-se que com a criação dos jogos educacionais por meio da Linguagem de Programação em blocos, é possível desenvolver o Pensamento Computacional nos estudantes, além de reforçar os conteúdos da Matemática de forma lúdica. Para validação da pesquisa, foram realizadas entrevistas após o estudo de caso com os alunos.

Além desta seção introdutória, o artigo contém a seção 2 que apresenta a metodologia do trabalho. A seção 3 aborda o planejamento e a execução do estudo de caso. A seção 4 contém os resultados e discussões. Finalmente, as conclusões e trabalhos futuros são apresentados na seção 5 .

\section{Metodologia do Trabalho}

O Scratch é uma Linguagem de Programação lúdica composta de blocos lógicos. A ferramenta possui uma interface gráfica intuitiva com itens de som e imagem que ajudam no desenvolvimento de histórias interativas, jogos, animações e possibilita o aluno compartilhar as suas criações de forma online [Resnick 2019]. O Scratch foi desenvolvido baseado na teoria Construcionista defendida por [Papert 1994].

Para este estudo de caso, as atividades com o Scracth foram baseadas nas 5 etapas da Espiral do Saber, sugerida por [Resnick 2007]. Desse modo, os alunos: (1) imaginam o que querem fazer (2) criam uma atividade baseada em suas ideias, (3) realizam as suas produções, (4) compartilham as ideias e criações com os colegas e (5) refletem em suas próprias experiências. Portanto, a metodologia definida poderá instigar a criatividade dos estudantes, os ajudando a pensar em novas ideias para realizar diferentes atividades. Por conseguinte, um estudo de caso foi realizado a fim de analisar como o Scratch e a Espiral do Saber em consonância, se comportam dentro de uma sala de aula. 
VIII Congresso Brasileiro de Informática na Educação (CBIE 2019)

Anais do XXV Workshop de Informática na Escola (WIE 2019)

\section{Estudo de Caso}

Inicialmente foi conversado com a Coordenação de Informática na Educação (CIE) sobre a possibilidade de realizar um trabalho relacionado a Pensamento Computacional na escola. Nesse sentido, para a escolha do nível de ensino, a CIE efetuou um sorteio, sendo escolhido o Ensino Fundamental I. A partir disso, a proposta foi direcionada ao $5^{\circ}$ ano para a disciplina Matemática, pois se tratava da turma que mais apresentava problemas no nível de ensino selecionado. Posteriormente, mediante uma primeira reunião entre CIE, professora e monitor de informática, definiu-se que as atividades estariam alinhadas ao plano de aula, sendo conduzidas pela professora responsável pela disciplina, mas apoiadas pela CIE e monitor de informática para o uso dos recursos tecnológicos. Dessa maneira, as atividades ocorreram nas aulas regulares, constituíram a nota do bimestre e não prejudicou o calendário escolar.

Diante disso, o projeto de criação de jogos educacionais com Scratch foi sugerido para ajudar os estudantes na disciplina Matemática. O Quadro 1 mostra as atividades desenvolvidas no projeto de criação de jogos com os alunos do $5^{\circ}$ ano do Ensino Fundamental I.

Quadro 1. Atividades desenvolvidas seguindo a Espiral do Saber.

\begin{tabular}{|c|c|}
\hline Etapa & Descrição das atividades \\
\hline Imaginar & $\begin{array}{l}\mathrm{Na} 1^{\circ} \text { etapa, foram apresentados alguns exemplos de games produzidos no Scratch, } \\
\text { com o intuito de despertar a curiosidade, melhorar a participação e instigar a } \\
\text { imaginação dos alunos. }\end{array}$ \\
\hline Criar & $\begin{array}{l}\mathrm{Na} 2^{\circ} \text { etapa, foram ensinados comandos de movimentos, como salto e } \\
\text { escorregamento. Além disso, foi mostrado como gravar e salvar um projeto, criar um } \\
\text { cenário e adicionar um personagem. Também, foi apresentado como mudar a } \\
\text { aparência do personagem, adicionar interação, diálogos e sons. Além disso, foi } \\
\text { trabalhado conceitos da programação, como: sequência (pensar de forma sistemática } \\
\text { na ordem de execução das instruções), iteração (comandos: repete e para sempre - } \\
\text { usados para repetir um bloco de instruções), condição (comandos: se, se...senão - } \\
\text { usados para checar a ocorrência da condição). Por meio desses recursos existentes na } \\
\text { ferramenta, os estudantes conseguiram criar os seus primeiros jogos e trabalhar o } \\
\text { Pensamento Computacional. }\end{array}$ \\
\hline Divertir-se & $\begin{array}{l}\text { Na } 3^{\circ} \text { etapa, a professora realizou alguns desafios matemáticos, envolvendo questões } \\
\text { de adição, subtração, multiplicação e divisão. Para isso, utilizou-se alguns Objetos de } \\
\text { Aprendizagens, como Lucky Drops, Space Race e Around the World, disponível } \\
\text { online no zdoz.com. Isso permitiu que os estudantes reforçassem os conteúdos, para } \\
\text { assim, adicionar esse conhecimento nos seus próprios jogos. }\end{array}$ \\
\hline Compartilhar & $\begin{array}{l}\text { Nessa etapa, estudantes de outras turmas usaram os jogos produzidos pela turma do } \\
5^{\circ} \text { ano. Dessa forma, a professora preparou uma exposição para mostrar os projetos } \\
\text { desenvolvidos no laboratório de informática durante as aulas de Matemática. }\end{array}$ \\
\hline Refletir & $\begin{array}{l}\text { Nessa etapa, a turma do } 5^{\circ} \text { ano refletiu sobre as atividades realizadas, motivações, } \\
\text { aprendizagem e dificuldades. Assim, os alunos puderam dar feedbacks acerca da } \\
\text { contribuição do projeto para a construção do conhecimento. }\end{array}$ \\
\hline
\end{tabular}

\section{Resultados e Discussões.}

No estudo de caso foi realizada uma análise dos dados qualitativos, obtidos a partir do feedback recebido na etapa Refletir da Espiral do Saber. Os comentários foram coletados por meio de Focus Group para melhorar a compreensão dos alunos sobre as atividades desenvolvidas. Focus Group é uma técnica qualitativa usada para coletar dados por meio de entrevistas em grupo, organizadas para discutir um determinado objeto, como uma 
VIII Congresso Brasileiro de Informática na Educação (CBIE 2019)

Anais do XXV Workshop de Informática na Escola (WIE 2019)

tecnologia [Grigoreanu et al. 2009]. Os depoimentos foram sobre o Pensamento Computacional para apoiar a aprendizagem da disciplina Matemática.

Em relação ao uso do Scratch com a Espiral do Saber, os estudantes acreditam que as metodologias combinadas para apoiar a aprendizagem das 4 operações matemáticas: proporcionam uma educação mais agradável e motivadora; dão um maior significado no ensino e aprendizagem; ajudam organizar as ideias de maneira lógica e sistemática (veja as citações Q1, Q2 e Q3 abaixo).

"Eu achei muito legal programar um joguinho. Foi bem melhor aprender assim, eu chegava até mais cedo na escola para participar. Foi divertido!" (Q01)

"Eu podia ajudar o personagem a resolver as contas de matemática. Isso me motivou a estudar mais, porque eu queria ajudar ele. Meu jogo me ensinou a multiplicar e até programar." (Q02).

"Eu me senti dentro do jogo. Gostei de programar, pensar em como seria meu jogo. Eu queria que ele fosse bem legal!” (Q03).

Os relatos mostram que os estudantes conseguiram aprender o conteúdo de maneira diferenciada, sem pressão ou cobrança, mas com incentivo de sua professora. Nesse contexto, foi percebida que a presença da professora é fundamental nos processos de ensino e aprendizagem, pois ela é quem desafia, orienta, faz o aluno refletir e se sentir seguro em sua produção. A orientação provocou interesse em ir ao laboratório de informática. Então, mesmo com dificuldades, por ser um projeto novo, os alunos puderam aprender matemática e computação, por meio da produção dos seus jogos.

Além disso, foi identificado que é possível trabalhar algumas competências e habilidades do Século XXI, como criatividade, autonomia, aprender fazendo, a partir do ensino da Computação (veja as citações Q04, Q05 e Q06 abaixo).

"Para eu criar o meu jogo, eu tive que pensar muito. Mas consegui fazer com ajuda da professora e do monitor. Tive que usar a minha imaginação!" (Q03).

"Eu podia fazer do jeito que eu achava melhor. Criei o meu cenário, meu personagem e os movimentos dele, por meio dos blocos. Fui o autor do meu jogo." (Q04).

"Eu tive que estudar mais, porque eu tinha que conhecer o conteúdo para fazer o meu jogo. Eu nem sabia como programar um computador.” (Q05).

Os comentários mostram que os conceitos básicos da computação, como sequência, iteração e condição, além dos recursos do Scratch ensinados, levaram o estudante a pensar de maneira lógica e sistemática, organizar as suas ideias, treinar a autoria, trabalhar a criatividade, melhorar a concentração, entre outras habilidades. Dessa forma, o Scratch e a Espiral do Saber demonstraram ser metodologias interessantes para os estudantes aprenderem conteúdos didáticos e desenvolverem competências e habilidades ligadas à Educação 4.0. De modo geral, o trabalho desenvolvido mostrou-se como uma alternativa a mais a favor da educação, possibilitando o acesso à cultura digital que é uma das competências definida na BNCC.

\section{Considerações Finais e Trabalhos Futuros}

Esse trabalho apresentou um estudo de caso que teve objetivo desenvolver o Pensamento Computacional, tendo como base a disciplina Matemática. As atividades foram realizadas com os alunos do $5^{\circ}$ ano do Ensino Fundamental I. Nesse sentido, o pontapé inicial desse trabalho foi gerar uma maior empatia nos alunos pela disciplina Matemática. 
Com a análise qualitativa, foi possível identificar que os alunos desenvolveram bem as habilidades de criatividade, autonomia e resolução de problemas. Os estudantes também forneceram feedback positivo sobre outras habilidades, como pensamento computacional, imaginação e inovação. Além disso, foram percebidos a aprendizagem das 4 operações da Matemática e o conhecimento adquirido de lógica de programação necessários para a produção dos jogos.

A experiência com o ensino da computação por meio dos jogos educacionais permitiu dinamizar a sala de aula. Isso poderá significar uma possível mudança de paradigma e favorecerá para a formação de cidadãos mais criativos, com autonomia para construir o próprio conhecimento. Desse modo, o ensino da computação se mostrou um bom aliado nos processos de ensino e aprendizagem da disciplina Matemática.

Com esta iniciativa, espera-se abrir novos caminhos para outros projetos no formato da Educação 4.0 em parceria com professores de outras disciplinas, níveis de ensino, envolvendo distintas tecnologias como robótica, realidade aumentada, internet das coisas, aprendizado de máquina, dentre outras. Dessa maneira, acredita-se que será possível melhorar o ensino, além de provocar mudanças positivas no cenário educacional brasileiro.

\section{Agradecimentos}

Esta publicação foi escrita com apoio financeiro do CNPq (Conselho Nacional Brasileiro de Desenvolvimento Científico e Tecnológico).

\section{Referências}

Aono, A. H., Silva, H. R. V., Musa, D. L., Pereira, V. A., Almeida, J. G. (2017). A Utilização do Scratch como Ferramenta no Ensino de Pensamento Computacional para Crianças. In: Workshop sobre Educação em Computação, 2017, São Paulo. Anais do CSBC, 2017.

BNCC. (2017). Base Nacional Comum Curricular - BNCC. Brasília: MEC. Disponível em: <http://download.basenacionalcomum.mec.gov.br/>. Acesso em: 15 mar. 2019.

Grigoreanu, V., Fernandez, R., Inkpen, K., Robertson, G. (2009). What Designers Want: Needs of Interactive Application Designers. In IEEE Symposium on Visual Languages and Human-Centric Computing, pp. 139-146.

Oliveira, T. M., Monteiro, W. M., Oliveira, F. C. S., Martins, D. J. S., Silva, A. L. L. (2017). Ensino de Raciocínio Lógico e Computação para Crianças: Experiências, In: Workshop sobre Educação em Computação, 2017, São Paulo. Anais do CSBC, 2017.

Papert, S. A. (1994). Máquina das Crianças: Repensando a Escola na Era da Informática. Porto Alegre: Artes Médicas, 1994.

Puncreobutr, P. (2016). Education 4.0: New Challenge of Learning. In St. Theresa Journal of Humanities and Social Sciences, v. 2, pp. 92-97.

Resnick, M. (2007). All I Really Need to Know (About Creative Thinking) I Learned (By Studying How Children Learn) in Kindergarten. ACM Creativity \& Cognition conference, Washington DC, 2007.

Resnick, M. (2019). The Next Generation of Scratch Teaches More Than Coding. EdSurge, 2019. 